\title{
Optimization of High-Performance-Concrete properties containing fine recycled aggregates using mixture design modeling
}

\author{
Tounsia Boudina \\ Research Laboratory of Civil Engineering (LRGC), University of Biskra, POBox 145, 07000 Biskra - Algeria \\ boudina_tounsia@yahoo.fr; boudina.tounsia@univ-biskra.d飞
}

\section{Dalila Benamara}

Laboratory of Civil Engineering at the University of Djelfa, POBox 3117, 17000 Djelfa - Algeria

benamaradalila2018@gmail.com; d.benamara@univ-djellfa.dr.

\section{Rebih Zaitri}

Civil Engineering Department, University of Djelfa, POBox 3117, 17000 Djelfa - Algeria. And Structures Rehabilitation and Materials Laboratory, University of Laghouat, Laghouat, Algeria

zrebih@yahoo.fr

ABSTRACT. This investigation means to optimize the properties of HighPerformance-Concrete (HPC) containing fine aggregates from concrete and brick wastes for different recycled aggregates substitution rates, using mixture design modeling.

To succeed this, the design of experiments (DOE) method was used. It is observed that slump, flexural and compressive strength of recycled concrete are significantly influenced by the content of natural sand (NS), recycled concrete aggregates (RCA) and recycled brick aggregates (RBA). The experimentally measured responses were successfully studied to develop a polynomial model, which represents slump, flexural strength and compressive strength at 7 day and 28 day of HPC. The significance and accuracy of the model was confirmed by statistical analysis and experimental verification. Under optimal conditions, the maximum desirability is 0.65 , which can be obtained by using only recycled sands, i.e. RBA $(9.5 \%)$ and RCA $(90.5 \%)$, and no natural sand. The statistical results show that the proposed models are well correlated with the experimental data.

KEYWORDS. High performance concrete; Recycled aggregates; Mixture design modelling; Physico-mechanical properties; Optimization.

\section{OPEN ACCESS}

Citation: Boudina, T., Benamara, D., Zaitri, R., Optimization of High-PerformanceConcrete properties containing fine recycled aggregates using mixture design modeling, Frattura ed Integrità Strutturale, 57 (2021) 5062.

Received: 01.04 .2021

Accepted: 11.05.2021 Published: 01.07.021

Copyright: (C) 2021 This is an open access article under the terms of the CC-BY 4.0, which permits unrestricted use, distribution, and reproduction in any medium, provided the original author and source are credited. 


\section{INTRODUCTION}

$\mathrm{S}$ everal research studies have been carried out in many countries for the purpose of studying the possibility of recovering construction and demolition wastes and use them as aggregates in new types of concrete [1-8].

The recycling of construction waste as aggregates plays an important role in protecting the environment. Since it allows, on one hand, to get rid of the debris resulting from the demolition of old buildings and / or from natural disasters, and on the other hand, to protect nature against the excessive exploitation of natural aggregate reserves. However, the problem of recycled aggregates from concrete and brick is the adhered mortar and its increased water absorption, which affected the properties of recycled concrete [9-10].

In Algeria, most of the concrete used is exclusively made with alluvial sand. It is worth acknowledging that many parts of the country suffer from a remarkable lack of good quality alluvial sand. In addition, environmental requirements, production costs, depletion of alluvial deposits and remoteness of construction sites with respect to these deposits are also factors that encourage practitioners to search other types of sand [11]. Currently, the use of high-performance concretes (HPCs), thanks to their high strength, offers good long-term durability to construction structures and allows saving up to $40 \%$ of materials [12-13]. For these reasons, the present work aims to investigate the effects of recycled sand from construction sites on -the physico-mechanical properties of high performance concretes. For this purpose, two types of recycled materials were been studied, namely recycled brick aggregates (RBA) and recycled concrete aggregates (RCA).

Recently, design of experiments DOE method has attracted the attention of many researchers in the construction field; [14-17]. This statistical method allows for a good control of the process, while performing a minimum number of tests; it also helps to determine the impact of each parameter when acting separately and when interacting with other parameters. However, in the field of recycled concrete, just few studies have used it [18-21].

In this article, a 3-factor, 4-level network mixture design-model based on the experimental design methodology was been applied. The factors for studying mixture design are the proportions of the constituents of the mixture (NS, RBA and RCA), these constituents are independent of each other. Moreover, the level represents the degree of accuracy levels chosen (25\%,50\%,75\% and 100\% in this study). The results obtained from the experimental tests and statistical analysis are presented as indicated by their substitution rates. So as to correctly valorise the incorporation of the aggregates of crushed brick and concrete, and to choose the most efficient optimal couples in the fresh and hardened states of concrete. It was decided to assess their impacts on the slump, the flexural and compressive strengths of concrete, at 7 and 28 days, in the form of a ternary iso-response diagram. The developed models were then compared with regard to their capacity to predict the intended responses, by analysing the coefficient of determination $\left(\mathrm{R}^{2}\right)$, adjusted coefficient of determination $\left(\mathrm{R}^{2}\right.$ adj), root mean square error $(\mathrm{RMSE})$, residual variance $(\mathrm{p}$-values $<0.05)$ and the graph of residuals according to the expected responses. To the best of knowledge, this is the first report using the modelling approach for mixture design with several statistical parameters, in forecasting the physical and mechanical properties of high performance concretes (HPCs) including recycled sand.

\section{INVESTIGATED MATERIALS}

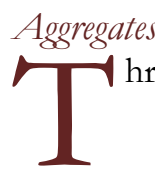

types of fine aggregates were then selected:

- The natural sand (NS) used is an alluvial sand, with nominal size of $4 \mathrm{~mm}$; the sand was dried at $105^{\circ} \mathrm{C}$.

- Two type of recycled fine aggregates (sands) were used in this research. The recycled concrete aggregates RCA $0 / 4$ and the recycled brick aggregates RBA $0 / 4$ was obtained by crushing an ordinary concrete and bricks respectively, using a jaw crusher. Both RCA and RBA were dried at $105^{\circ} \mathrm{C}$.

Two fraction size $(4 / 8$ and $8 / 16 \mathrm{~mm})$ of natural coarse aggregates $(\mathrm{NCA})$ were used. The NCA are a crushed limestone obtained from a local quarry in Algeria.

The physical properties of fine and coarse aggregates are shown in Tab. 1. The grain size curves are plotted according to the recommendations of standard NF EN 933-1; they are shown in the Fig. 1.

\section{Cement}

The cement used is of type CEMI $52.5 \mathrm{~N}$, produced by the local Cement Plant in Algeria, with a fineness of $3461 \mathrm{~cm}^{2} / \mathrm{g}$ and density of $3150 \mathrm{~kg} / \mathrm{m}^{3}$ was used in accordance with Standard EN 196-3 and 6. 


\section{Adjuvant}

The adjuvant used is a new generation high-water-reducing superplasticizer of the MEDAFLOW 145 type. It is a solution of polycarboxylates, 31\% dry extract, light pitch color, and $\mathrm{pH}$ between 5 and 6.

\section{Silica fume}

The apparent density of silica fume is $650\left(\mathrm{~kg} / \mathrm{m}^{3}\right)$, the actual density is $2240\left(\mathrm{~kg} / \mathrm{m}^{3}\right)$ and its Blaine specific surface is $23000\left(\mathrm{~cm}^{2} / \mathrm{g}\right)$. Tab. 2 presented the chemical compositions of cement and silica fume (SF).

\begin{tabular}{|c|c|c|c|c|c|c|}
\hline \multirow{2}{*}{$\begin{array}{c}\text { Type of Aggregate } \\
\text { Characteristics }\end{array}$} & \multicolumn{2}{|l|}{ Norme } & \multicolumn{2}{|c|}{ Fine aggregates } & \multicolumn{2}{|c|}{ Coarse aggregates } \\
\hline & / & NS & RCA & RBA & NCA $4 / 8$ & NCA $8 / 16$ \\
\hline Fineness modulus & NF EN 12620 & 3.51 & 4.51 & 3.53 & - & - \\
\hline Absolute density $\left(\mathrm{g} / \mathrm{cm}^{3}\right)$ & NF EN 1097-6 & 2.68 & 2.57 & 2.32 & 2.55 & 2.62 \\
\hline Apparent density $\left(\mathrm{g} / \mathrm{cm}^{3}\right)$ & NF EN 1097-6 & 1.53 & 1.131 & 1.23 & 1.19 & 1.60 \\
\hline Sand equivalent $(\%)$ & NF EN 933-8 & 75.89 & 75.93 & 88.22 & - & - \\
\hline Compactness $(\%)$ & NF P 18-555 & 58 & 50.93 & 40.46 & - & - \\
\hline Water absorption (\%) & NF EN 1097-6 & 1 & 8 & 14 & 0.04 & 0.03 \\
\hline
\end{tabular}

Table 1: Physical and mechanical characteristics of fine and coarse aggregates.

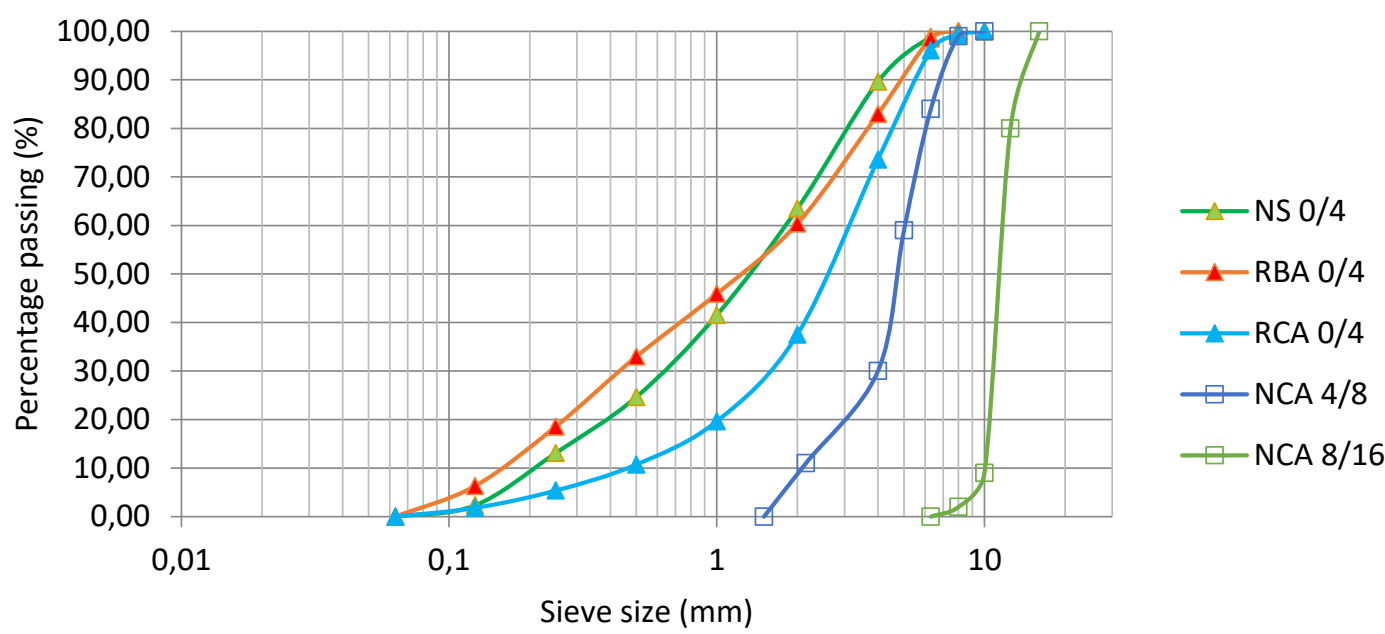

Figure 1: Grading curves of fine and coarse aggregates used.

\begin{tabular}{cccccccccc}
\hline The samples & $\begin{array}{c}\mathrm{SiO}_{2} \\
\%\end{array}$ & $\begin{array}{c}\mathrm{AI}_{2} \mathrm{O}_{3} \\
\%\end{array}$ & $\begin{array}{c}\mathrm{Fe}_{2} \mathrm{O}_{3} \\
\%\end{array}$ & $\begin{array}{c}\mathrm{CaO} \\
\%\end{array}$ & $\begin{array}{c}\mathrm{MgO} \\
\%\end{array}$ & $\begin{array}{c}\mathrm{SO}_{3} \\
\%\end{array}$ & $\begin{array}{c}\mathrm{Na}_{2} \mathrm{O} \\
\%\end{array}$ & $\begin{array}{c}\mathrm{K}_{2} \mathrm{O} \\
\%\end{array}$ & $\begin{array}{c}\text { P.A.F. } \\
\%\end{array}$ \\
Cement (C) & 21.70 & 4.27 & 4.83 & 64.11 & 1.35 & 1.59 & 0.08 & 0.32 & 0.99 \\
Silica Fume (SF) & 93.17 & 0.60 & 1.25 & 1.40 & 1.02 & 2.30 & 1.00 & - & - \\
\hline
\end{tabular}

Table 2: Chemical compositions of the constituents. 


\section{SAMPLE PREPARATION METHOD}

7 he formulation of High-performance concretes (HPCs) is based on the composition method developed by Aitcin at the University of Sherbrooke [12]. A control concrete HPC 15 (CC) was prepared with natural aggregates, crushed gravel and alluvial sand (NCA 4/8, NCA 8/16 and NS).

The replacement of natural sand by recycled one, was done by replacing a percentage of NS by its equivalent volume of RBA and RCA. Only recycled sands were pre-wetted, for a period of $24 \mathrm{~h}$ before mixing, in order to avoid the possible absorption of mixing water by recycled aggregates [22]. They were then introduced into the mixer on a saturated-surface dry state; the other aggregates were used in their natural condition. Fig. 2 shows concrete composition for fifteen HPCs with various compositions (natural sand/ recycled sand).

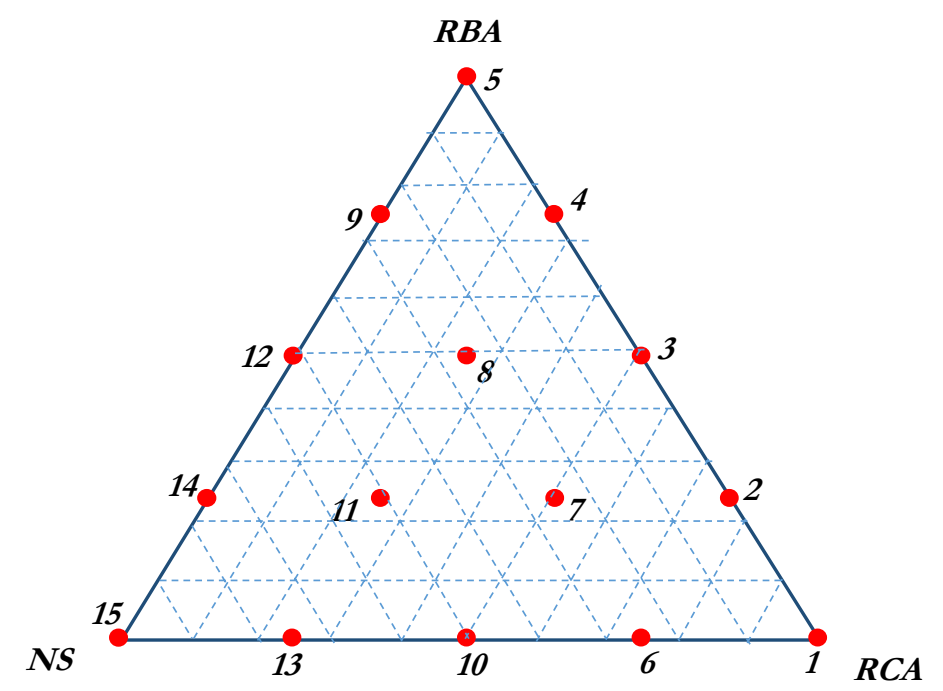

Figure 2: Representation of the triangular network with 15 combinations (15 tests).

The present work is expected to deal with a mixed-level design with 3 factors, i.e. natural sand (NS 0/4), and the two type of recycled fine aggregates, i.e. recycled brick aggregates RBA and recycled concrete aggregates RCA, taken in mass proportions; their sum must be equal to unity, with $75 \%$ substitution of alluvial sand. A constraint was put on the proportion of one-constituent (substitution of NS sand does not exceed $75 \%$ in this case); a coding of the proportions was required. By considering, the remaining quantity that represents the unit, and the proportions of the points of experiments was deduced from the classic mixture design (Tab. 3).

It is worth noting that these factors are dependent on each other. The experimental domain must therefore satisfy the following condition:

$$
\% \mathrm{NS}+\% \mathrm{RBA}+\% \mathrm{RCA}=100 \%
$$

A second-order polynomial model was used with three non-independent variables. The proportions of these factors are presented in Fig. 2.

\section{TEST METHODS}

he experimental program aimed to perform three physico-mechanical characterization tests: workability, compressive strength and flexural strength at 7 and 28 days. The workability tests were carried out by measuring the slump using the Abrams slump cone test. For this, the concrete was introduced into a standardized conical mold in accordance with the LCPC technique and in conformity with Standard NF EN 12350-2. It is worth indicating that the Abrams cone test is very simple to perform, rapid and relatively reliable. 
On the other hand, the mechanical characterization was accomplished once the compressive and flexural strengths were measured at 7 and 28 days. The mechanical behavior of all the HPC mixtures was investigated in simple bending ( 3 points) and uniaxial compression on prismatic test specimens of dimensions $\left(70 \times 70 \times 280 \mathrm{~mm}^{3}\right)$. Moreover, three samples were tested, at each deadline, in simple bending on the bending frame of a Matest press with a maximum capacity of 25 $\mathrm{kN}$. It should be noted that the change rate was set at $0.05 \pm 0.01 \mathrm{MPa} / \mathrm{s}$ until failure, in accordance with the recommendations of standard NF P 18-407. The six half-test pieces resulting from bending failure were then subjected to uniaxial compression on the compression frame of a double-quadrant Controls brand press that has a maximum capacity of $200 \mathrm{kN}$, at a loading speed of $0.5 \mathrm{kN} / \mathrm{s}$. The specimens were cured in water until the age of testing.

\begin{tabular}{|c|c|c|c|c|c|c|c|c|c|c|}
\hline Mixture & $\begin{array}{l}\text { Cement } \\
\left(\mathrm{kg} / \mathrm{m}^{3}\right)\end{array}$ & $\begin{array}{c}\text { Silica } \\
\left(\mathrm{kg} / \mathrm{m}^{3}\right)\end{array}$ & $\begin{array}{c}\mathrm{NS} \\
\left(\mathrm{kg} / \mathrm{m}^{3}\right)\end{array}$ & $\begin{array}{c}\mathrm{RBA} \\
\left(\mathrm{kg} / \mathrm{m}^{3}\right)\end{array}$ & $\begin{array}{c}\text { RCA } \\
\left(\mathrm{kg} / \mathrm{m}^{3}\right)\end{array}$ & $\begin{array}{c}\mathrm{NCA} \\
4 / 8 \\
\left(\mathrm{~kg} / \mathrm{m}^{3}\right)\end{array}$ & $\begin{array}{c}\text { NCA } \\
8 / 16 \\
\left(\mathrm{~kg} / \mathrm{m}^{3}\right)\end{array}$ & $\begin{array}{c}\mathrm{W} \\
\left(1 / \mathrm{m}^{3}\right)\end{array}$ & $\mathrm{W} / \mathrm{C}$ & $\begin{array}{l}\text { Sp } \\
\text { (L) }\end{array}$ \\
\hline HPC1 & & & 182.70 & 0 & 532.32 & & & & & \\
\hline HPC2 & & & 182.70 & 120.05 & 399.24 & & & & & \\
\hline HPC3 & & & 182.70 & 240.10 & 266.16 & & & & & \\
\hline HPC4 & & & 182.70 & 360.15 & 133.08 & & & & & \\
\hline HPC5 & & & 182.70 & 480.20 & 0 & & & & & \\
\hline HPC6 & & & 321.16 & 0 & 399.24 & & & & & \\
\hline HPC7 & & & 321.16 & 120.05 & 266.16 & & & & & \\
\hline HPC8 & 450 & 50 & 321.16 & 240.10 & 133.08 & 273 & 777 & 150 & 0.3 & 6 \\
\hline HPC9 & & & 321.16 & 360.15 & 0 & & & & & \\
\hline HPC10 & & & 459.61 & 0 & 266.16 & & & & & \\
\hline HPC11 & & & 459.61 & 120.05 & 133.08 & & & & & \\
\hline HPC12 & & & 459.61 & 240.10 & 0 & & & & & \\
\hline HPC13 & & & 598.07 & 0.00 & 133.08 & & & & & \\
\hline HPC14 & & & 598.07 & 120.05 & 0 & & & & & \\
\hline HPC15 & & & 736.53 & 0 & 0 & & & & & \\
\hline
\end{tabular}

Table 3: Mixture proportions for $1 \mathrm{~m}^{3}$ of concrete $\left[\mathrm{kg} / \mathrm{m}^{3}\right]$.

\section{RESULTS AND DISCUSSION}

A ccording to the mixture design modelling, the responses as a function of the substitution rate for the three factors, i.e. NS, RBA and RCA. Witch can be fully exploited in the development of the mathematical models and predict the properties of concrete mixtures (slump, compressive strength and flexural strength) for different parameters process values. These models make it easier to assess the effect of each factor separately, and in combination with the other factors. Tab. 4 depicts the results of the experimental characterization tests carried out in the laboratory; these results were obtained on the basis of the developed mixture design.

\section{Effect of $\mathrm{RCA}$ and $\mathrm{RBA}$ on Slump}

The measured slump changed from very plastic workability to plastic workability, for the different substitution rates of recycled sands. 


\begin{tabular}{cccccc}
\hline Mixture & $\begin{array}{c}\mathrm{S} \\
(\mathrm{cm})\end{array}$ & $\begin{array}{c}\mathrm{CS} \text { at 7 d } \\
(\mathrm{MPa})\end{array}$ & $\begin{array}{c}\mathrm{CS} \text { at 28 d } \\
(\mathrm{MPa})\end{array}$ & $\begin{array}{c}\text { FS at 7 d } \\
(\mathrm{MPa})\end{array}$ & $\begin{array}{c}\text { FS at 28 d } \\
(\mathrm{MPa})\end{array}$ \\
HPC1 & 18 & 58.76 & 82.54 & 7.40 & 12.13 \\
HPC2 & 16.5 & 55.52 & 82.8 & 8.02 & 11.37 \\
HPC3 & 13 & 52.07 & 81.72 & 7.75 & 11.52 \\
HPC4 & 9 & 51.6 & 81.83 & 7.97 & 11.58 \\
HPC5 & 6 & 46.88 & 77.1 & 7.55 & 11.53 \\
HPC6 & 14 & 54.97 & 76.45 & 7.52 & 10.17 \\
HPC7 & 10 & 52.4 & 78.14 & 7.74 & 10.29 \\
HPC8 & 8 & 47.32 & 77.1 & 7.33 & 10.3 \\
HPC9 & 7 & 45.49 & 75 & 7.17 & 10.72 \\
HPC10 & 9 & 50.35 & 72.1 & 7.72 & 9.97 \\
HPC11 & 8 & 50.22 & 74 & 7.42 & 10.87 \\
HPC12 & 8 & 43.83 & 74.26 & 7.07 & 10.91 \\
HPC13 & 9 & 55.33 & 71.84 & 8.21 & 10.86 \\
HPC14 & 10 & 53.55 & 76.3 & 7.62 & 11.63 \\
HPC15 & 16 & 63.2 & 80.24 & 8.75 & 12.55 \\
\hline
\end{tabular}

Table 4: Experimental results of characterization tests.

\begin{tabular}{cc}
\hline \multicolumn{2}{c}{ Summary of Adjustment } \\
$\mathrm{R}^{2}$ & 0.955131 \\
$\mathrm{R}^{2}$ adjusted & 0.930203 \\
Root of the mean squared error & 0.994628 \\
Average response & 10.76667 \\
Observations (or weighted sums) & 15 \\
\hline
\end{tabular}

Table 5: Model estimation parameters for the slump under consideration

The concrete slump values were measured during the tests, which were compared with the results predicted by the generated model. The analyses of statistical parameters presented in Tab. 5 and Fig. 3(a) indicate that the Eq. (2) represent adequately the actual relationship between the independent variables and the responses. The ANOVA results for the slump show P-value $<0.0001$ (Fig. 3(a)), which implies that the $\mathrm{R}^{2}$ and adjusted coefficients ( $\mathrm{R}^{2}$ adj) were calculated to check the adequacy and fitness of the model. The values of $\left(\mathrm{R}^{2}\right)$ and $\left(\mathrm{R}^{2}\right.$ adj) are close to 1 , which implies also, that there are excellent correlations between the predicted and experimental models (Fig. 3(a)). The mathematical model used in the slump test is given by the following equation:

$$
\begin{aligned}
S(\mathrm{~cm})= & 15.064285714 \times \mathrm{NS}+6.2071428571 \times \mathrm{RBA}+19.171428571 \times \mathrm{RCA}+ \\
& +\mathrm{NS} \times(\mathrm{RB} A \times-11.71428571)+\mathrm{NS} \times(\mathrm{RCA} \times-31.85714286)+\mathrm{RB} A \times(\mathrm{R} C A \times 0.1428751429)
\end{aligned}
$$


This model, as expressed by Eq. (2), allows observing that the slump value is strongly conditioned by the increase in the mass proportion of RCA first, and then by the proportioning of NS and RBA. It is worth mentioning that the slump increase is mainly attributed to the physical behavior of RCA fines. Therefore, increasing the RCA content could result in a significant growth in workability values. It is widely acknowledged that sands from demolition concrete are rich in fines, and can therefore be used to significantly increase the workability of concrete. Moreover, it should be noted that the couples of factors (NS*RBA, NS*RCA and RBA*RCA) in the polynomial have negative effects. This may be assigned to the high quantity of fines which were responsible for the higher water demand. Indeed, when the content of recycled binary mixtures increases, the quantity of water required for wetting the entire surface of grains gets higher; this leads to slump decline in the manufactured concretes.

Furthermore, the iso-response curves of slump for high performance concretes (HPCs) are function to the percentage of substitution of the three types of sand are depicted in Fig. 3(b). which suggests that the existence of recycled aggregates reduces the workability of concrete in the fresh state, particularly for RBA proportions greater than $75 \%$, i.e. $56.25 \%$ of the total sand mass, with a small percentage of RCA with respect to reference concrete (HPC15). Whereas, it is noted that demolished waste concrete fines significantly improve the workability of concrete, especially for RCA dosages greater than $75 \%$, i.e. HPC2 and HPC6 which exhibit the highest slump values, i.e. $16.5 \mathrm{~cm}$ and $14 \mathrm{~cm}$, respectively, in comparison with the other types of concrete under study.

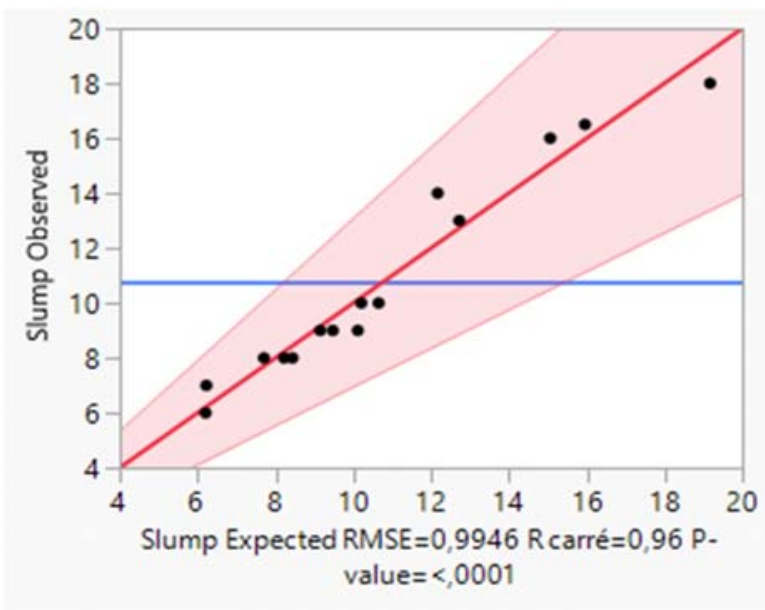

(a)

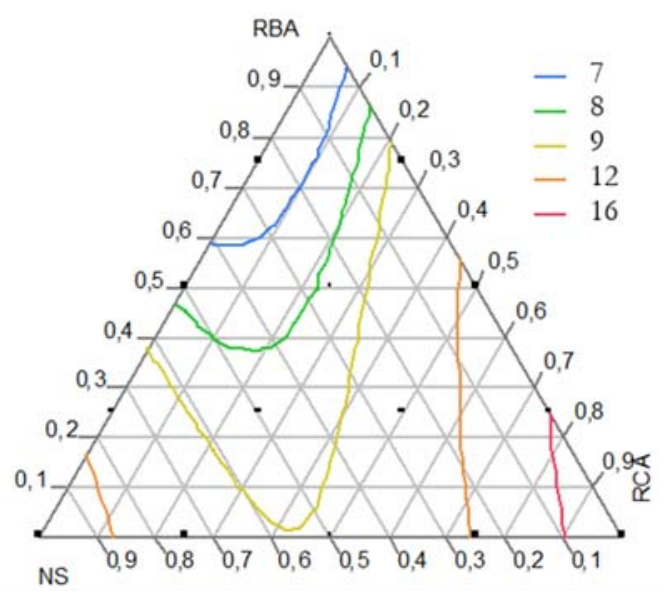

(b)

Figure 3: (a) Graphical representation of observed and predicted slump for the 15 tests, (b) Iso-response curves of slump of HPCs as function of substitution rates of the three types of sand (NS, RBA, RCA).

\section{Effect of $R C A$ and $R B A$ on compressive and flexural strength}

Mechanical characterization was carried out using compressive and flexural strength measurements to assess the effect of RCA and RBA recycled aggregates.

\begin{tabular}{ccc}
\hline & $\begin{array}{c}\text { Summary of Adjustment } \\
\text { R }\end{array}$ & CS at 28 d \\
$\mathrm{R}^{2}$ adjusted & 0.940175 & 0.942657 \\
Root of the mean squared error & 0.906939 & 0.9108 \\
Average response & 1.566473 & 1.099557 \\
Observations (or weighted sums) & 52.09933 & 77.448 \\
\hline
\end{tabular}

Table 6: Compressive strength model parameter estimates (CS at $7 \mathrm{~d}$ and CS at $28 \mathrm{~d}$ ), Summary of Adjustment. 


\begin{tabular}{ccc}
\hline & Summary of Adjustment & \\
& FS at 7 d & FS at 28 d \\
$\mathrm{R}^{2}$ & 0.938866 & 0.922873 \\
$\mathrm{R}^{2}$ adjusted & 0.904902 & 0.880024 \\
Root of the mean squared error & 0.132442 & 0.259156 \\
Average response & 7.682667 & 11.09333 \\
\hline
\end{tabular}

Table 7: Flexural strength model parameter estimates (FS at $7 \mathrm{~d}$ and FS at $28 \mathrm{~d}$ ), Summary of Adjustment.

As clearly indicated in Tabs. 6-7, the models simulated show a good regression model with a large value of the correlation coefficients i.e $\mathrm{R}^{2}=0.9401,0.9426,0.9388$ and 0.9228 for CS at $7 \mathrm{~d}$, CS at $28 \mathrm{~d}$, FS at $7 \mathrm{~d}$ and FS at $28 \mathrm{~d}$, respectively. The results obtained from experimental trials using mixture design models for CS at $7 \mathrm{~d}$ and CS at $28 \mathrm{~d}$ have been predicted by using the Eqns. (3) - (4):

$$
\begin{aligned}
& C S \text { at } 7 d(\mathrm{MPa})=63.055286 \times \mathrm{NS}+47.311714 \times \mathrm{RBA}+58.871714 \times \mathrm{RCA}+\mathrm{NS} \times(\mathrm{RB} A \times-36.04857)+ \\
& \mathrm{NS} \times(\mathrm{R} C A \times-34.10571)+R B A \times(R C A \times 1.1371429) \\
& C S \text { at } 28 d(M P a)=79.258 \times \mathrm{NS}+77.443714286 \times \mathrm{RBA}+82.763 \times \mathrm{RCA}+\mathrm{NS} \times(\mathrm{RB} A \times-14.10857143)+ \\
& +\mathrm{NS} \times(R C A \times-34.82)+R B A \times(R C A \times 10.951428571)
\end{aligned}
$$

Based on these models, it can be noted that CS at $28 \mathrm{~d}$ is first conditioned by the RCA content, next by the increase in the NS content, then by the RBA content and finally by the coupled effect of the RBA * RCA. On the other hand, it was found that the effects of the couple NS * RBA and NS * RCA cause a reduction in the compressive strength.

The experimental results obtained for the mechanical strength are compared with the expected responses given by the JMP7 [23] software, they are represented graphically in Fig. 4. The models developed were then compared with respect to their ability to predict the expected responses such as presented in Tabs. 6-7. And by analysing the graph of the residues of expected results. One can clearly assert that since the graphical representation of the residues in terms of the expected values (Fig. 5) has a random shape, the fluctuations of residues are relatively small and regular for CS and FS at 28 days. In both cases, the developed models exhibit a slight deviation, there is no information left to extract.

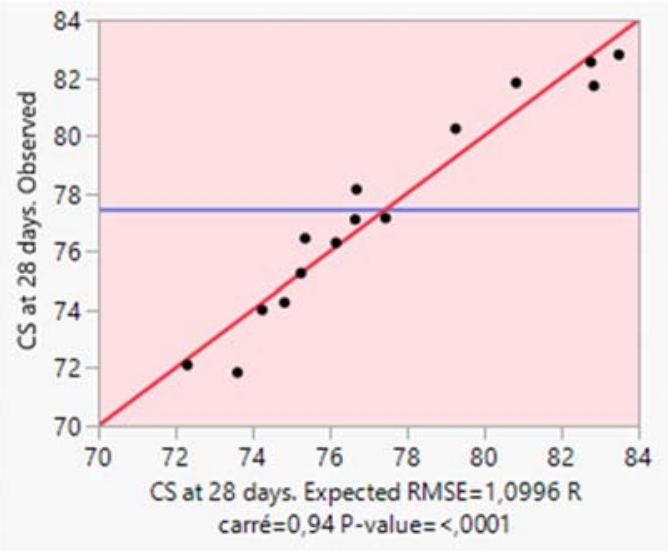

(a) CS at $28 \mathrm{~d}$

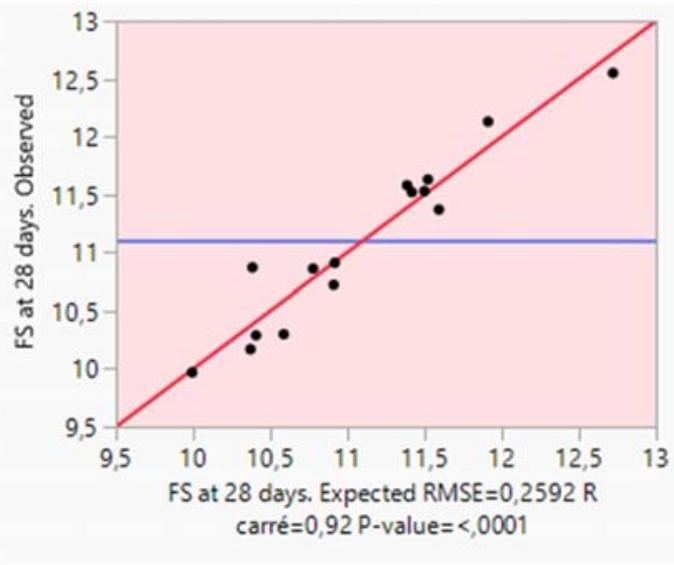

(b) FS at $28 \mathrm{~d}$

Figure 4: Graph representing the observed values as a function of the predicted values for the mechanical strength. 


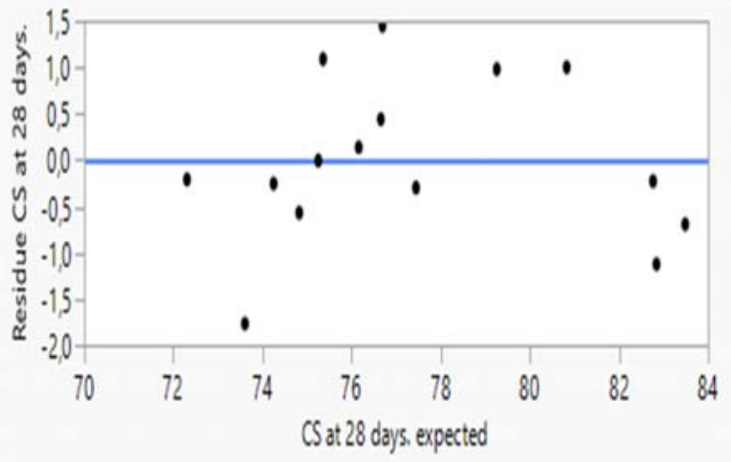

(a) CS at $28 \mathrm{~d}$

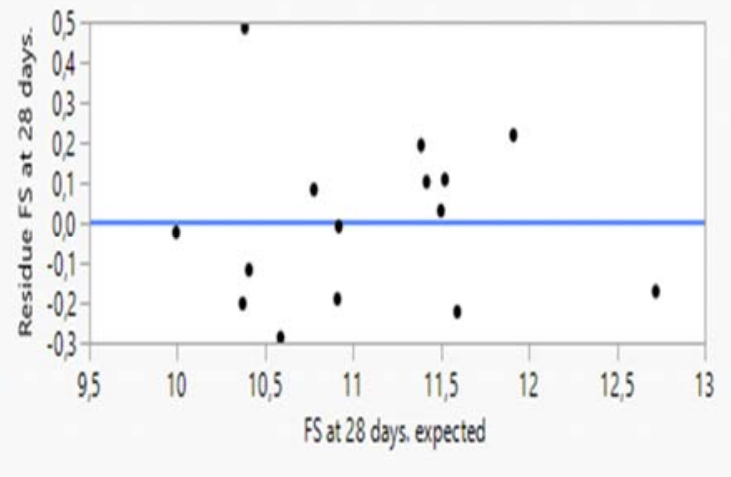

(b) FS at $28 \mathrm{~d}$

Figure 5: Graph perform the residues as a function of the predicted values at 28 days.

Figs. 6 and 7 clearly show that with experimental designs method, one obtains the maximum information with the minimum number of experiments.

The prediction profiler is used to study the impact of changes in study factors on predicted values. The curves in the profiler show the power of the impact of changes in each factor on responses. The prediction profiler of the compressive strength (CS) as a function of the substitution percentages for the three factors is shown in Fig. 8. This prediction profiler clearly indicates that the maximum of CS at $28 \mathrm{~d}$ can be achieved when the proportions of the three factors are $0 \%$ for NS, $25 \%$ for RBA and $75 \%$ for RCA; for these three substitution percentages, the compressive strength (CS) reaches a maximum value of $83.48 \mathrm{MPa}$, as shown in Fig. 8. Note that the incorporation of RCA above $75 \%$ slightly reduced the compressive strength. On the other hand, it is considerable to mention that RBA has a negative effect on the compressive strength CS in 28 days as it continuously generates lower responses than that of control concrete. This decrease can also be explained by the fact that recycled aggregates are less resistant, especially the brick sands, and therefore the mechanical strength of concrete should decrease.

According to the statistical model resulting from the response studied, it is clear that the resistance at 7 days has a very different trend on the ternary iso-response curve than the resistance at 28 days, as indicated by the coefficients of each factor and the negative influences of different coupled effects. If we are aiming for a high value of the compressive strength studied at 7 days, it will be necessary to choose a mixture with high RBA contents. If a high response of CS at 28 days desired, a mixture rich of NS and RCA will be chosen.

In conclusion, the factors do not influence by the same value at 7 and 28 days. RBA sand speeds the strength of concrete at 7 days while RCA gives an improved strength at 28 days.

The prediction Eqn. (5)-(6) shows the evolution of the flexural strengths at 7 and 28 days:

$$
\begin{aligned}
F S 7 d(M P a)= & 8.7431429 \times \mathrm{NS}+7.5938571 \times \mathrm{RBA}+7.4781429 \times \mathrm{RCA}+\mathrm{NS} \times(\mathrm{RB} A \times-4.368571)+ \\
& \mathrm{NS} \times(\mathrm{RCA} \times-1.425714)+\mathrm{RB} A \times(\mathrm{RCA} \times 1.7028571) \\
F S 28 d(\mathrm{MPa})= & 12.721428571 \times \mathrm{NS}+11.499285714 \times \mathrm{RBA}+11.911428571 \times \mathrm{RCA}+ \\
& +\mathrm{NS} \times(\mathrm{RB} A \times-4.768571429)+\mathrm{NS} \times(\mathrm{RCA} \times-9.291425871)+\mathrm{RB} A \times(\mathrm{RCA} \times-1.151428571)
\end{aligned}
$$

Furthermore, it is worth adding that the flexural strength FS at 7 days is also influenced by the percentages of the substitution of RBA and RCA. One may observe that after 7 days, the flexural strengths of HPC's with the substitution of RBA sand, achieved higher values of FS, than HPC's with RCA sand at the same percent of substations of these two sands presented in Eq. (5). This is mainly attributed to the pozzolanic reaction of fines from RBA brick waste sand i.e. calcined clay [24-26], which will have the effect of lowering the rate of portlandite $(\mathrm{CH})$ and the production of new CSHs. This has led to better densification of the cement matrix. 

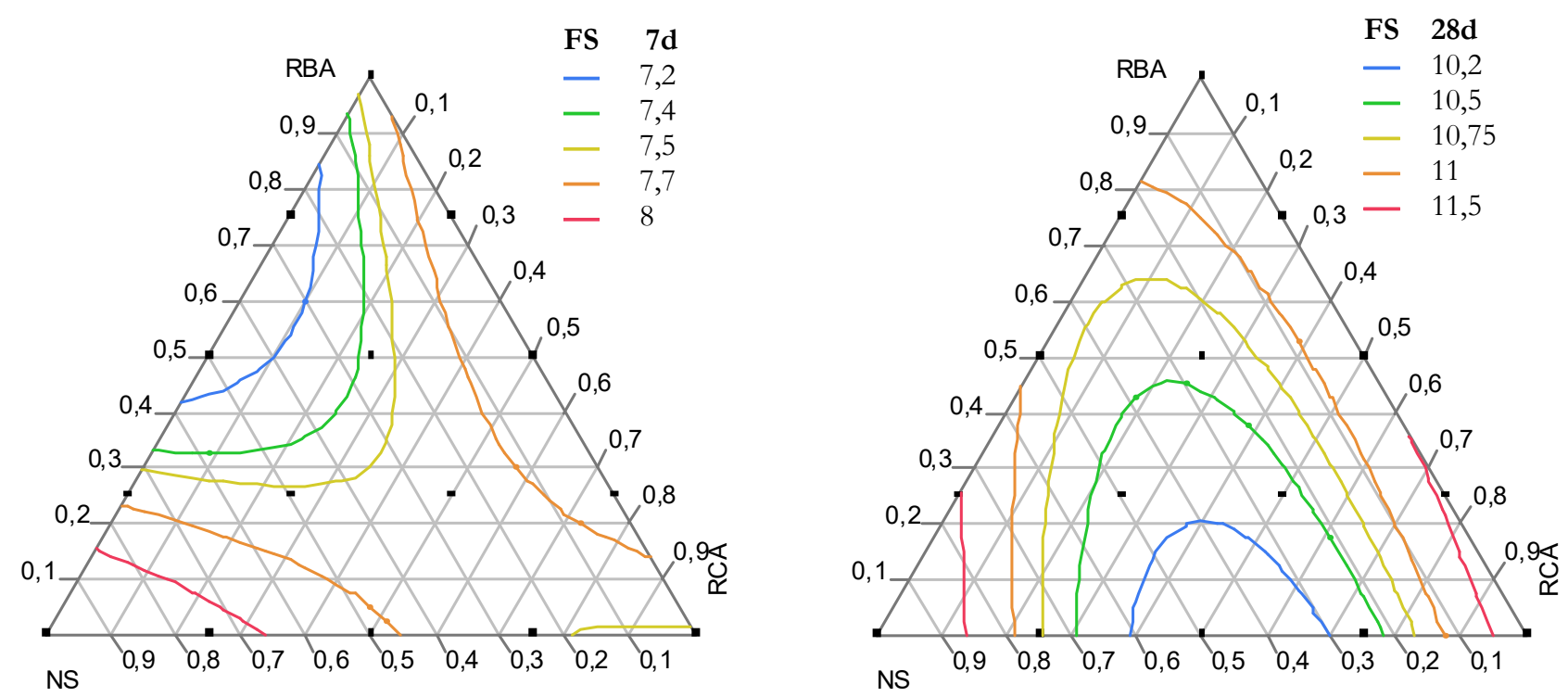

Figure 6: Iso-response curves for the flexural strength at 7 days and 28 days.
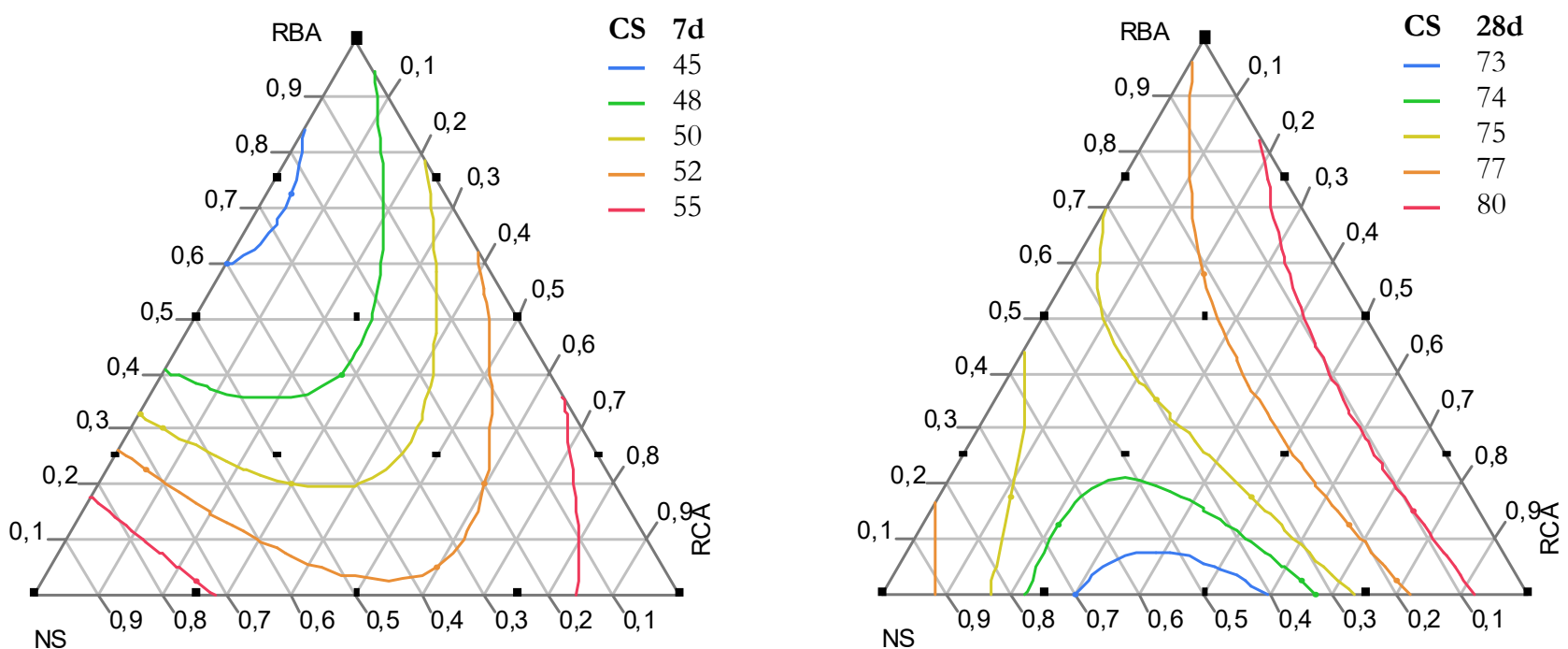

Figure 7: Iso-response curves for the compressive strength at 7 days and 28 days.

\section{OPTIMIZATION}

7 he search for the optimal proportions of fine recycled aggregates leading to the optimization of the recovery of fine recycled aggregates (RBA and RCA) having optimal responses, from previously established models, was done using the response profiler whose desirability value close to 1 corresponds to the maximum values of the physicomechanical properties.

The optimization was performed using the desirability function which combines all the optimization targets into one (desirability).

According to this study, the maximum desirability is 0.65 (Prevision profiler) which can be reached for HPC without natural sand, by mixing the two recycled sands $9.5 \%$ of RBA and $90.5 \%$ of RCA. The optimized composition of the mixture gives: Slump=17.94 cm, FS 7d= 7.63MPa, FS 28d=11.77 MPa, CS $7 \mathrm{~d}=57.86 \mathrm{MPa}$ et CS $28 \mathrm{~d}=83.20 \mathrm{MPa}$. 
Furthermore, this optimization also showing that HPC can be produced with recycled sands from brick and concrete waste and makes it possible to achieve better properties to natural HPCs (HPC 15).

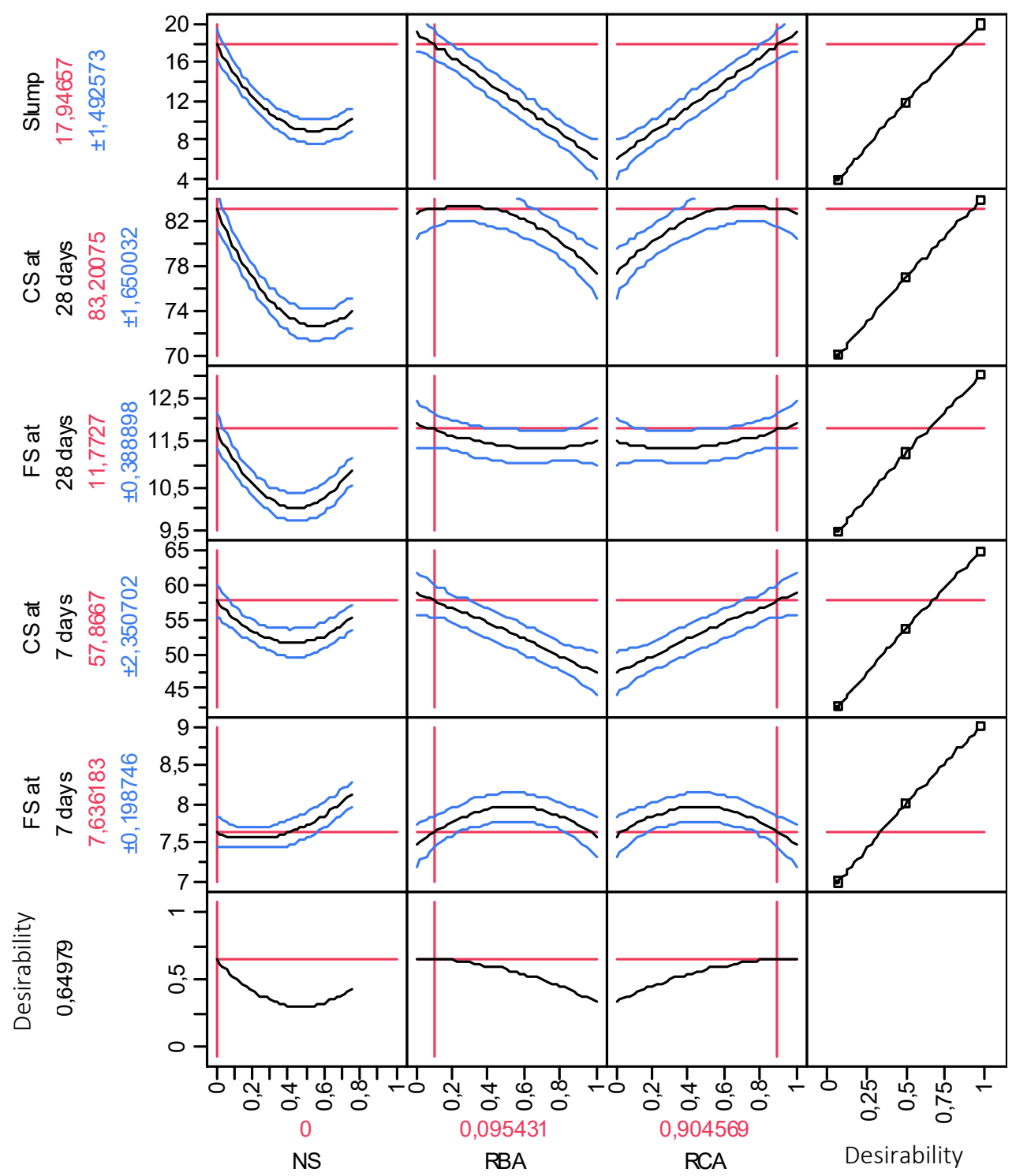

Figure 8: Prevision profiler for predicting optimal conditions for the formulation of recycled fine aggregate BHP.

\section{CONCLUSIONS}

7 he present research aimed mainly at assessing the effects of incorporating brick waste aggregates and concrete demolition waste aggregates on the physico-mechanical properties of concrete. Through experimental tests and analyses of each formulation, which contains different factors, with various substitution rates, and using the mixture design approach, it was found that a good agreement exists between the results of the mathematical models and those of the experimental tests, which validates the various considerable data on the effects of each of the recorded parameters.

In light of the outcomes got right now, the following ends could be drawn:

- The modelling of the mixture design method utilized right now has demonstrated to be a powerful procedure for considering the impacts of the three types of sand (NS 0/4, RBA 0/4 and RCA 0/4) in binary and ternary frameworks on the fresh and hardened concrete states. The advantage of modelling results studied using the 
prediction equation is that it can evaluate all possible responses without carrying out all experiments. The measurements obtained during the tests allow developing polynomial models of prediction for the slump and mechanical strength of HPC's with fine recycled aggregates.

- It should also be noted that the compressive strength of the formulated concrete is comparable to that of control concrete. Moreover, it was found that following 28 days, the compressive strength (CS) reached a maximum value of $83.48 \mathrm{MPa}$ with factors values of $25 \% \mathrm{RBA}$, and $75 \% \mathrm{RCA}$. And HPC's based on RBA sand presented greater values of flexural strength at 7 days than HPC's based on RCA sand, it was revealed that this is due to the RBA fines pozzolanic reaction and the production of new CSHs, which leads to better cement matrix densification.

- These findings demonstrate the robustness and usefulness of mixture design to model, predict and optimize the HPCs fine aggregate composition using RCA and RBA sands. It can therefore be concluded that HPC can be produced with recycled aggregates which has better properties.

- Substitution of natural aggregates with recycled aggregates for the production of the new concrete offers a new aggregate resource and allows saving natural materials.

It is worth mentioning that the physical and mechanical properties of the formulated concretes are encouraging. Moreover, the economic, environmental and technical aspects are also very interesting, which supports this initiative of recovering brick waste and concrete demolition waste to be used as building materials.

\section{NOMENCLATURE}

NS: Natural Sand

RBA: Recycled Brick Aggregates

RCA: Recycled Concrete Aggregates

NCA: Natural Coarse Aggregates

HPC: High Performance Concrete

SF: $\quad$ Silica Fume

Sp: $\quad$ Superplasticizer

C: $\quad$ Cement

(W/C): (Water / Cement) ratio

$\mathrm{S}$ (cm): Slump

CS at $7 d$ : Compressive Strength at 7 days.

CS at 28d: Compressive Strength at 28 days.

FS at $7 \mathrm{~d}$ : Flexural Strength at 7 days.

FS at 28d: Flexural Strength at 28 days.

DOE: Design of Experiments.

\section{REFERENCES}

[1] Tayeh, B. A. M. Al Saffar, D. M. and Alyousef, R. (2020). The utilization of recycled aggregate in high performance concrete: a review. J. of Mat. Res. And Tech., 9(4), pp. 8469-8481. DOI: 10.1016/j.jmrt.2020.05.126.

[2] Anamarie, C.R. Saylisse, D.W. Torres, G. and Arsenio, C.F. (2020). Experimental design of concrete mixtures using recycled plastic, fly ash, and silica nanoparticles. Construction and Building Materials., 254, 119207. DOI: $10.1016 /$ j.conbuildmat.2020.119207

[3] Silva, R.V. de Brito, J. and Dhir, R.K. (2018). Fresh-state performance of recycled aggregate concrete: A review. J. Constr. and Build. Mater., 178, pp. 19-31. DOI: 10.1016/j.conbuildmat.2018.05.149.

[4] Zheng, C. Lou, C. Du, G. Li, X. Liu, Z. Li, L. (2018). Mechanical Properties of Recycled Concrete with Demolished Waste Concrete Aggregate and Clay Brick Aggregate, Results in Physics. DOI: 10.1016/j.rinp.2018.04.061.

[5] Job Thomas, Nassif Nazeer Thaickavil and P.M. Wilson. (2018). Strength and durability of concrete containing crushed concrete aggregates, J. of Build. Eng., DOI: 10.1016/j.jobe.2018.05.007.

[6] Omary, S. Ghorbel, E. and Wardeh, G. (2016). Relationships between recycled concrete aggregates characteristics and recycled aggregates concretes properties. J. Constr. and Build. Mater., 108, pp. 163-174.

DOI: $10.1016 /$ j.conbuildmat.2016.01.042. 
[7] Kenai, S. and Debieb, F. (2011), Caractérisation de la durabilité des bétons recyclés à base de gros et fins granulats de briques et de béton concassé, Mater. \& Structr., 44, pp. 815-824. DOI: 10.1617/s11527-010-9668-7.

[8] Berredjem, L. Arabi, N. Molez, L. and Jauberthie, R. (2015). Propriétés mécaniques et durabilité des bétons à base de graviers et sables recyclés issus de béton de démolition. Deuxième Conférence Internationale Francophone Nouveaux Matériaux et Durabilité (NoMad 2015), Nov 2015, Douai, France. Nouveaux Matériaux et Durabilité, https://hal.archives-ouvertes.fr/hal-01366521.

[9] Juan, M.S. and Gutiérrez, P.A. (2009). Study on the influence of attached mortar content on the properties of recycled concrete aggregate, Constr. Build. Mater. 23, pp. 872-877. DOI: 10.1016/j.conbuildmat.2008.04.012.

[10] Tu, T.Y. Chen, Y.Y. and Hwang, C.L. (2006). Properties of HPC with recycled aggregates, Cem. Concr. Res, 36, pp. 943-950. DOI: 10.1016/j.cemconres.2005.11.022.

[11] Shi, X. Mukhopadhyay, A. Zollinger, D. Grasley, Z. (2019). Economic input-output life cycle assessment of concrete pavement containing recycled concrete aggregate. Journal of Cleaner Production, 225, pp. 414-425.

DOI: $10.1016 /$ j.jclepro.2019.03.288.

[12] Aitcin, C. P. (2001), Bétons Haute Performance, Edition Eyrolles, IBSN 2-21201323-X, pp. 683, Paris.

[13] Manikanta, D. Ravella, D. P. Yadav, J. M. (2021). Mechanical and durability characteristics of high performance selfcompacting concrete containing flyash, silica fume and graphene oxide. J. of Materials Today. DOI: $10.1016 /$ j.matpr.2021.01.684.

[14] Goupy, J. and Creighton, L. (2007). Introduction to design of experiments with JMP examples. 3rd ed. Cary (NC): SAS Institute, pp. 438. https://trove.nla.gov.au/version/43645151.

[15] Mayandi Venkatesan, Qammer Zaib, Izhar Hussain Shah, Hung Suck Park. (2019). Optimum utilization of waste foundry sand and fly ash for geopolymer concrete synthesis using D-optimal mixture design of experiments. Resources, Conservation \& Recycling, 148, pp. 114-123. DOI: 10.1016/j.resconrec.2019.05.008.

[16] Varanda, C. Portugal, I. Ribeiro, J. Silva, A.M.S. Silva. C.M. (2017). Optimization of bitumen formulations using mixture design of experiments (MDOE). J. Constr. and Build. Mater., 156, pp. 611-620.

DOI: 10.1016/j.conbuildmat.2017.08.146.

[17] Bun Kim Ngun, Hasmaliza Mohamad, Ken-ichi Katsumata, Kiyoshi Okada, Zainal Arifin Ahmad. (2014) Using design of mixture experiments to optimize triaxial ceramic tile compositions incorporating Cambodian clays. Applied Clay Science 87, pp. 97-107. DOI: 10.1016/j.clay.2013.11.037.

[18] Cabral, A. E. B., Schalch, V., Dal Molin, D. C. C., Ribeiro, J. L. D. (2010), Mechanical properties modeling of recycled aggregate concrete, J. Constr. and Build. Mater., 24, pp. 421-430, DOI: 10.1016/j.conbuildmat.2009.10.011.

[19] Lovato, P. S., Possan, E. Dal Molin, D. C. C., Masuero, A. B., Ribeiro, J. L. D. (2012), Modeling of mechanical properties and durability of recycled aggregate concretes, J. Constr. and Build. Mater., 26, pp. 437-447.

DOI: 10.1016/j.conbuildmat.2011.06.043.

[20] Hammoudi, A. Moussaceb, K. Belebchouche, C. and Dahmoune, D. (2019). Comparison of artificial neural network (ANN) and response surface methodology (RSM) prediction in compressive strength of recycled concrete aggregates. J. Constr. and Build. Mater., 209, pp. 425-436.

DOI: $10.1016 /$ j.conbuildmat.2019.03.119.

[21] Gabriella Puente de Andrade, Gabriela de Castro Polisseni, Marco Pepe, Romildo Dias Toledo Filho. (2020). Design of structural concrete mixtures containing fine recycled concrete aggregate using packing model. J. Constr. and Build. Mater., 252, 119091. DOI: 10.1016/j.conbuildmat.2020.119091.

[22] Arabi, N. and Berredjem, L. (2011). Valorisation des déchets de démolition comme granulats pour bétons, déchets revue francophone d'écologie industrielle, 60, pp. 25-30, https://doi.org/10.4267/dechets-sciences-techniques.2765.

[23] JMP (2018), version 14.0. SAS institute Inc., Cary, NC, 1989-2019.

[24] Bazaz, J. B and Khayati M. (2012). Properties and performance of concrete made with recycled low-quality crushed brick. J. Mater. Civ. Eng., 24(4), pp. 330-338. DOI: 10.1061/(ASCE)MT.1943-5533.0000385.

[25] Ge, Z. Gao, Z. Sun, R. Zheng, L. (2012). Mix design of concrete with recycled clay-brick-powder using the orthogonal design method. J. Constr. and Build. Mater., 31, pp. 289-293. DOI: 10.1016/j.conbuildmat.2012.01.002.

[26] Afshinnia, K and Poursaee, A. (2015). The potential of ground clay brick to mitigate Alkali-Silica Reaction in mortar prepared with highly reactive aggregate. J. Constr. and Build. Mater., 95, pp. 164-170.

DOI: $10.1016 /$ j.conbuildmat.2015.07.155. 